\title{
AOR
}

Selected Papers of \#AoIR2019:

The 20 $0^{\text {th }}$ Annual Conference of the

Association of Internet Researchers

Brisbane, Australia / 2-5 October 2019

\section{INFANCY WITHIN ADVERTISING PLATFORM: YOUNG CHILDREN EXPERIENCES ON A VIDEO-SHARING WEBSITE.}

\author{
Amanda Aggio \\ Massey University
}

This paper investigates how young children experience digital advertising platforms. Specifically, it focuses on young children's participation in the YouTube app as part of an advertising mechanism that captures and profits from their views and attention. An innovative trans-disciplinary bridge between digital labour studies, biopolitics theory and qualitative research on children online has been developed to achieve this aim.

Children going online at progressively earlier ages raises questions around what they are experiencing in the virtual world (Chaudron, 2015). Platform capitalism such as Google Alphabet and Facebook profit from data collected about digital media use. In the advertising platform, revenue is generated mostly not through raw data, but rather on the analysis of personal data made by unrevealed algorithms which is sold to advertisers. This process of making a profit based on user information leads to issues around trust and the confluence of surveillance and profit. Most of the Internet users do not have access to the data collected on them, as well as the algorithm's rationale that constantly offers outcomes. For instance, the quantification of children's practices on digital platforms feed algorithms that model online contents which further influence children's lives. This interference places algorithms as a biopolitical tool for capitalism over children's attention (Lupton, 2016). Precisely, digital visual technologies operate directly on the body of individuals when it creates new perceptive models and new flows of visual information (Crary, 1992). This biopower that captures attention and that governs life itself is what rules Biopolitics, which cannot be dissociable from the capitalist economy (Foucault \& Hurley, 1998; Rose, 1999).

The studies of platform capitalism build on questions around the persistence of Marxist concepts such as surplus labour, surplus value, and labour exploitation within the economy of digital platforms. In the platform economic context, the class structure is different from the class structure offline, and the central difference is that on the Internet there is no restriction of age. Within the digital advertising platform, children are putting their senses and attention to work for corporations via free access to services and contents to accumulate data and profit strategically.

Suggested Citation (APA): Aggio, A. (2019, October 2-5). Infancy Within Advertising Platform: Young Children Experiences on A Video-Sharing Website. Paper presented at AolR 2019: The 20th Annual Conference of the Association of Internet Researchers. Brisbane, Australia: AolR. Retrieved from http://spir.aoir.org. 


\section{AOR}

Selected Papers of \#AoIR2019:

The 20 $0^{\text {th }}$ Annual Conference of the

Association of Internet Researchers

Brisbane, Australia / 2-5 October 2019

It is valuable to note that children's participation in the media as part of a profit mechanism is not a novelty; the idea of television audiences as a commodity, and the relationships between advertisers, audiences and broadcasters were widely discussed in the 1980s and 90s(Smythe, 1981). However, digital media, especially mobile devices, have taken this commodification to a completely new level. For instance, previous generations of young children grew up watching TV, an apparatus adjusted by an adult and shared with others through a single device. Mobile technology, on the other hand, is most often used by a single person and can be manipulated even by an infant. Even considering that young children's use of mobile devices is parent-directed in some ways [e.g., parents selecting children's apps or children experiencing them with parents (Arrow, 2017)], there is still a 'babysitting' aspect to media. In New Zealand, $82 \%$ of children under 4 years old spent time in a room where the television was turned on even if they are not watching it, and over three-quarters of them $(77 \%, \mathrm{n}=4729)$ use digital technologies other than television on a usual day (Morton, 2017). Further, research shows that children are going online at younger ages. In the United States of America, $95 \%$ of families with children aged 8 and under have a smartphone (up from 41\% in 2011), and the average amount of time spent with digital devices daily has increased from 5 minutes in 2011 to 48 minutes in 2017. The percentage of children that have their device rocketed from $<1 \%$ in 2011 to $42 \%$ in 2017 . Most importantly, $72 \%$ of these children spent their time with media watching videos (Sense, 2017).

One cannot deny that digital technologies have brought new possibilities to domains such as education and health. Some educational apps have proved to be useful in teaching contexts and social relationships, as well as being helpful in health problems like cognition disorders. For instance, literacy apps like LetterWorks can help children with reading (D'Agostino, Rodgers, Harmey, \& Brownfield, 2016), and the game Pokemon Go has increased daily physical activities of those using it (Althoff, White, \& Horvitz, 2016). However, it is important to consider and examine the underlying economic models through which these applications and services operate in order to grasp elements of their functioning that are not necessarily immediately obvious to the children who use them (Beller, 2006; Fuchs, 2010a). The susceptibility of young children allows for potential risk factors that should not be overlooked.

I am undertaking qualitative research that is examining the role of children, and their understanding of this role, within the political economy of digital platforms. The extent to which parents/caregivers and teachers are knowledgeable about the models of data mining, statistical profiling and corporate profit-generation that occur within this digital environment is also being investigated. This investigation merges critical and empirical analyses of the virtual context and discursive contents through 


\section{AOR}

Selected Papers of \#AoIR2019:

The 20 $0^{\text {th }}$ Annual Conference of the

Association of Internet Researchers

Brisbane, Australia / 2-5 October 2019

interviews and observation. Ultimately, this work aims to encourage dialogue between parents, schools, and authorities about children's welfare online.

\section{References}

Althoff, T., White, R. W., \& Horvitz, E. (2016). Influence of pokémon go on physical activity: Study and implications. Journal of Medical Internet Research, 18(12). doi:10.2196/jmir.6759

Arrow, A. F., B. (2017). Digital Technologies in the Literate Lives of Young Children. In C. J. M. A. W. Arrow (Ed.), Literacy in the Early Years: Reflections on International Research and Practice (pp. 221-238). Singapore: Springer, Singapore.

Beller, J. (2006). The cinematic mode of production attention economy and the society of the spectacle. Hanover, N.H.: Dartmouth College Press.

Chaudron, S. (2015). Young Children (0-8) and digital technology: A qualitative exploratory study across seven countries. VA, Italy.

Crary, J. (1992). Techniques of the observer: on vision and modernity in the nineteenth century. Cambridge, Mass.: MIT Press.

D'Agostino, J. V., Rodgers, E., Harmey, S., \& Brownfield, K. (2016). Introducing an iPad App into Literacy Instruction for Struggling Readers: Teacher Perceptions and Student Outcomes. Journal of Early Childhood Literacy, 16(4), 522-548.

Foucault, M., \& Hurley, R. (1998). The history of sexuality. Volume 1, The will to knowledge. Harmondsworth: Penguin.

Fuchs, C. (2010a). Labor in Informational Capitalism and on the Internet. The Information Society, 26(3), 179-196. doi:10.1080/01972241003712215 


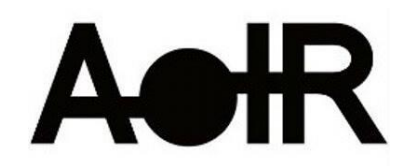

Selected Papers of \#AoIR2019:

The $20^{\text {th }}$ Annual Conference of the

Association of Internet Researchers

Brisbane, Australia / 2-5 October 2019

Lupton, D. (2016). The quantified self. Malden, MA: Polity.

Morton, S. (2017). Growing up in New Zealand. New Zealand: Auckland University.

Rose, N. S. (1999). Powers of freedom : reframing political thought. Cambridge:

Cambridge University Press.

Sense, C. (2017). The Common Sense Census: media use by kids age zero to eight.

Smythe, D. (1981). Dependency Road: Communications, Capitalism,

Consciousness, and Canada. Norwwod, NJ: Praeger. 